\title{
Preparation of Amorphous Carbon Films and Evaluation of Its Optical Properties and Gas Barrier Property*
}

\author{
Yuuki OHSONE**, Hidetaka NISHI**, Masanori SAITO**, Masaki SUZUKI**, \\ Hiroya MURAKAMI** and Naoto OHTAKE*** \\ ** Tokyo Institute of Technology, Dept. of Mechanical Sci. and Eng. \\ 2-12-1, O-okayama, Meguro, Tokyo 152-8552, Japan \\ *** Nagoya University, Dept. of Materials, Physics and Energy Eng. \\ Furo-cho, Chikusa, Nagoya 464-8603, Japan \\ E-mail: ohtaken@plasma.numse.nagoya-u.ac.jp
}

\begin{abstract}
Hydrogenerated amorphous carbon ( $a$-C:H) films can improve oxygen gas barrier characteristics of plastic food containers, by coating it on the surfaces of such containers, and is intended to enhance the preservative quality. However, it has a problem that the degradation of optical transparency in the visible light range blocks the view of the inner content. In this study, we aimed to reduce the oxygen transmission rate (OTR) as well as to improve optical transparency, and fabricated $a$-C:H films by the pulse plasma chemical vapor deposition (CVD) method on polyethylene terephthalate (PET) films. First, it is clarified that the gas barrier performance in the $a$-C:H film in the vicinity of the PET boundary surface was lower than that of bulk a-C:H film. Secondly, the OTR and optical transparency of $a-\mathrm{C}: \mathrm{H}$ films deposited not only from $\mathrm{C}_{2} \mathrm{H}_{2}$ but also from $\mathrm{Si}\left(\mathrm{CH}_{3}\right)_{4}$ were investigated in detail. The $a$ - $\mathrm{C}: \mathrm{H}$ film deposited from $\mathrm{Si}\left(\mathrm{CH}_{3}\right)_{4}$ shows high transmittance of $87 \%$ for visible light with a relatively low OTR of $3.2 \mathrm{cc} /\left(\mathrm{m}^{2}\right.$. atm $\cdot$ day).
\end{abstract}

Key words : Gas Barrier, Amorphous Carbon Film, Diamond-Like Carbon (DLC), Transparency, Oxygen Transmission Rate, Optical Property

\section{Introduction}

Hydrogenerated amorphous carbon ( $a-\mathrm{C}: \mathrm{H})$ film is mainly comprised of carbon and hydrogen. The atomic density of $a-\mathrm{C}: \mathrm{H}$ is high and it can form four-coordinated structures because carbon is the smallest atomic number in the elements of group 14. Hence, $a-\mathrm{C}: \mathrm{H}$ film has various excellent properties such as high hardness, low friction and wear, electrical insulation, chemical inertness and gas barrier performance. Many mechanical applications of $a$-C:H film have already been put to practical use such as industrial tools, hard disk drives ${ }^{(1)}$ and razors. Regarding the electrical fields, photovoltaic ${ }^{(2)}$ and field emission ${ }^{(3)}$ properties are still being investigated. The technology using the gas barrier performance of $a-\mathrm{C}: \mathrm{H}$ film has already been industrially commercialized ${ }^{(4),(5)}$. However, it still has the problem that the degradation of optical transparency in the visible light range block the view of the inner content and also worsens the look and feel. The purpose of this study is to reduce the oxygen transmission rate (OTR) and also to improve the optical transparency by depositing a-C:H film on PET film from acetylene $\left(\mathrm{C}_{2} \mathrm{H}_{2}\right)$ and tetramethylsilane (TMS).

\section{Experimental}

The $a-\mathrm{C}: \mathrm{H}$ films were fabricated on $\mathrm{p}-\mathrm{Si}<100>$ substrates and PET films (thickness: 50 $\mu \mathrm{m})$ by the pulse plasma CVD method. The applied pulse voltage was $-8 \mathrm{kV}$. The full width at half maximum of the applied pulse voltage was approximately $150 \mathrm{~ns}$. The deposition pressure

${ }^{*}$ Received 24 Sep., 2008 (No. 08-0675) [DOI: 10.1299/jmmp.3.691] 


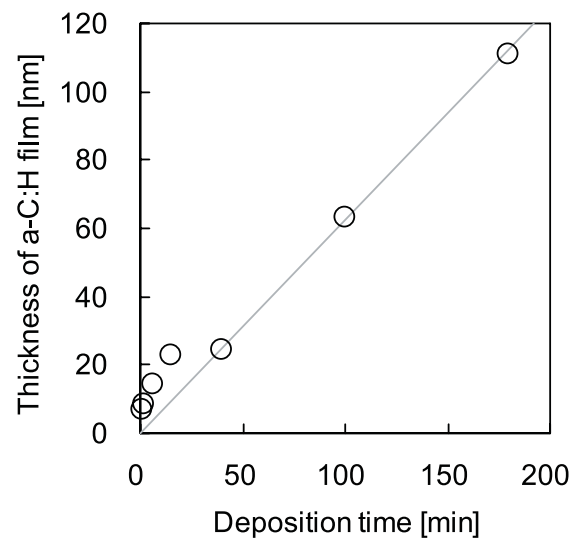

Fig. 1 Dependence of $a$-C:H film thickness on deposition time (acetylene).

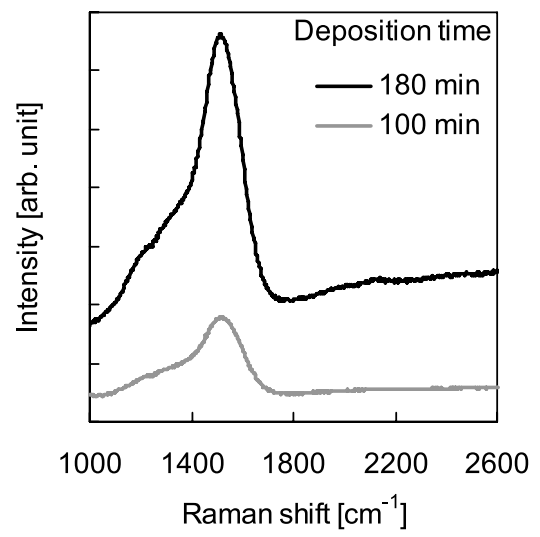

Fig. 2 Raman spectra of $a$-C:H films deposited from acetylene.

was $4 \mathrm{~Pa}$. We used acetylene and TMS as source gases. The deposition time was varied from $1 \mathrm{~min}$ to $180 \mathrm{~min}$ with each source gas. Transmittance was measured with a photometer (NDH-300A: Nippon Denshoku Industries Co. Ltd., Japan). The yellow index of $a$-C:H film on PET substrates was measured with a spectral colorimeter (SE-2000: Nippon Denshoku Industries Co. Ltd., Japan). The OTR of $a-\mathrm{C}: \mathrm{H}$ film was measured with oxygen permeation instruments (OX-TRAN 2/21: MOCON, Inc.) to evaluate the gas barrier performance. The transmittance, yellow index and OTR of $a$-C:H films on PET substrates were measured. The thicknesses of $a-\mathrm{C}: \mathrm{H}$ films on $\mathrm{Si}$ substrates were measured with a stylus surface profilometer. The analysis of $a-\mathrm{C}: \mathrm{H}$ films on Si substrates was performed by Raman scattering spectroscopy, Fourier transform infrared spectroscopy (FT-IR), Rutherford backscattering and elastic recoil detection analysis (RBS/ERDA).

\section{Results and Discussion}

\subsection{Deposition from acetylene}

Acetylene was used as the source gas. Figure 1 shows the dependence of the $a-\mathrm{C}: \mathrm{H}$ film thickness on deposition time. The deposition rate at the beginning of deposition was much higher than those at deposition times longer than $50 \mathrm{~min}$.

Two typical Raman spectra for films with deposition times of $100 \mathrm{~min}$ and $180 \mathrm{~min}$ are shown in Fig. 2. These spectra show that both films are typical amorphous carbon films.

Figure 3 shows the dependence of the transmittance and yellow index on $a-\mathrm{C}: \mathrm{H}$ film thickness. The thicker film had the lower transparency. Equation (1) below is the BeerLambert law that describes optical absorption. $I_{0}, I_{1}, \alpha$ and $L$ are the incident intensity, transmitted intensity, absorption coefficient and optical path length, respectively. By applying experimental values to them, the transmittance and $a-\mathrm{C}: \mathrm{H}$ film thickness can be described as $I_{0} / I_{1}$ and $L$, respectively. Then, because the relationship between $a$-C:H film thickness and 


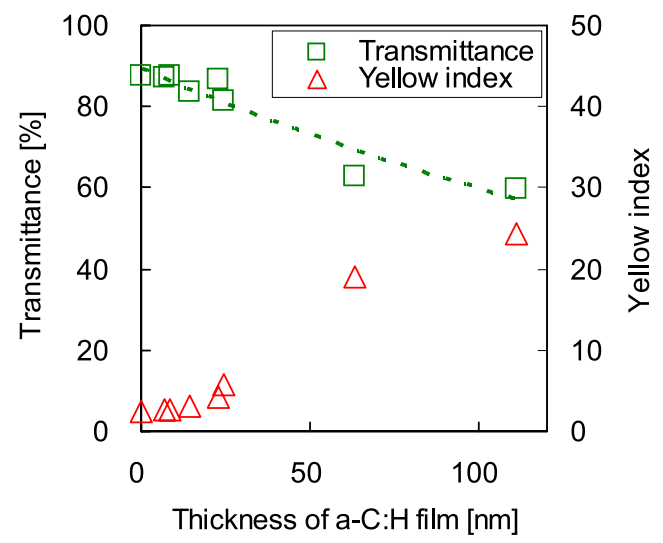

Fig. 3 Dependence of transmittance and yellow index on $a$-C:H film thickness.

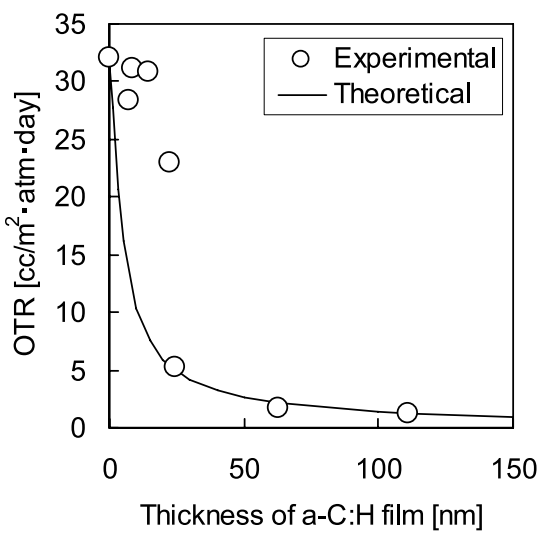

Fig. 4 Oxygen transmission rate vs thickness of $a-\mathrm{C}: \mathrm{H}$ film (circles: experimental, line: numerical).

measured values of transmittance followed their exponential approximation curve, the degradation of transmittance was assumed to be mainly attributed to optical absorption in $a-\mathrm{C}: \mathrm{H}$ films.

$$
\ln \frac{I_{1}}{I_{0}}=-\alpha L
$$

Figure 4 shows the dependence of the OTR on the thickness of $a$-C:H film. An increase in the $a-\mathrm{C}: \mathrm{H}$ film thickness caused the OTR to be low. However, the decrease of OTR at thicknesses below $20 \mathrm{~nm}$ was nominal. On the grounds of this phenomenon and the high deposition rate at the beginning of deposition, it is deduced that oxygen molecules are more transmissive there.

We calculated OTR using the diffusion equation. The diffusion coefficients of PET film and $a$-C:H film were calculated to be $2.9 \times 10^{-14} \mathrm{~m}^{2} / \mathrm{s}$ and $6.2 \times 10^{-18} \mathrm{~m}^{2} / \mathrm{s}$, respectively using eq. (2). Diffusion equation (3) was discretized to eq. (4). Then OTR was calculated from the oxygen concentration distribution, for various $a-\mathrm{C}: \mathrm{H}$ film thicknesses. Experimentally measured OTR with the $a$-C:H film thickness less than $20 \mathrm{~nm}$ was significantly higher than the calculated OTR. Therefore it could lead to the results that the actual $a$-C:H film quality was inhomogeneous and that the gas barrier performance in the $a-\mathrm{C}: \mathrm{H}$ film in the vicinity of the PET boundary surface was low.

$$
\begin{aligned}
& q=-D \frac{\partial C}{\partial x} \\
& \frac{\partial C}{\partial t}=D\left(\frac{\partial^{2} C}{\partial x^{2}}\right) \\
& \frac{C_{n}-C_{n, \text { previous }}}{\Delta t}=D\left(\frac{1}{\Delta x} \cdot \frac{C_{n+\Delta x}+C_{n-\Delta x}}{\Delta x}\right)
\end{aligned}
$$




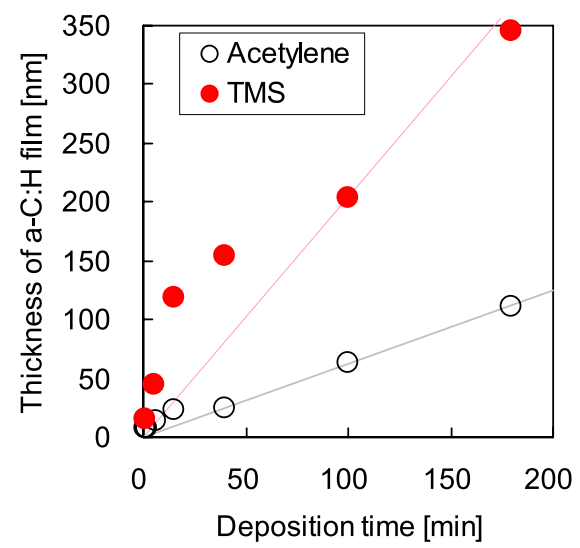

Fig. 5 Relationship between thickness of $a-\mathrm{C}: \mathrm{H}$ film and deposition time.

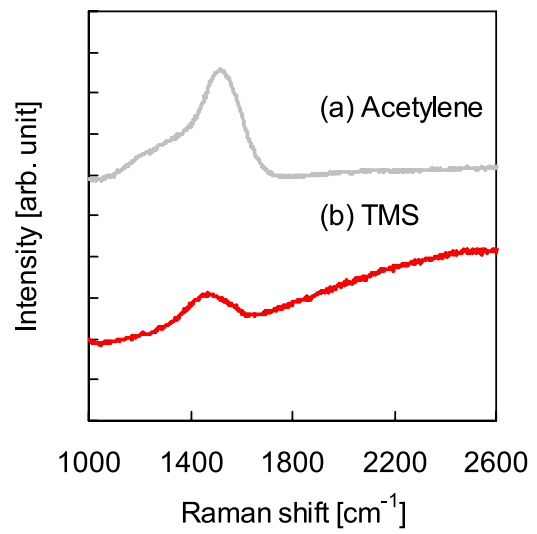

Fig. 6 Raman spectra of $a$-C:H films deposited from acetylene and TMS.

\subsection{Deposition from tetramethylsilane}

In this section, TMS was used as the source gas. Figure 5 shows the dependence of $a$ $\mathrm{C}: \mathrm{H}$ film thickness on deposition time. The deposition rate of the TMS source was higher than that of the acetylene source. Figure 6 shows Raman spectra of the $a-\mathrm{C}: \mathrm{H}$ films deposited from acetylene (deposition time: $100 \mathrm{~min}$ ) and from TMS (deposition time: $40 \mathrm{~min}$ ). The baseline of the TMS spectrum increased with higher wave number, thus hydrogen composition in the $a$-C:H film deposited from TMS seems to be high $^{(6)}$. Moreover the G-peak position of the TMS spectrum shifted to a lower wave number compared with the acetylene spectrum. It is considered that the compressive stress of six-carbon-membered ring structures is relieved and that $\mathrm{Si}-\mathrm{C}$ bonds weaken adjacent $\mathrm{C}-\mathrm{C}$ bonds vibration.

Figure 7 shows FT-IR spectra of the $a$-C:H films deposited from TMS (deposition time: $180 \mathrm{~min}$ ) and from acetylene (deposition time: $15 \mathrm{~min}$ ). The spectrum of TMS had the peaks of Si-C, Si-O and Si-H vibrations. The film deposited from TMS contained O, $\mathrm{H}$ and $\mathrm{Si}$ that formed backbone structures and $\mathrm{H}$ terminations in the film. Abbas et al. analyzed the $s p^{3} /\left(s p^{2}+s p^{3}\right)$ ratio of $a$-C:H films deposited from acetylene and TMS, by X-ray photoemission spectroscopy (XPS) $)^{(7)}$. They revealed that the $s p^{3} /\left(s p^{2}+s p^{3}\right)$ ratios were $52.4 \%$ and $69.3 \%$ when the number density of $\mathrm{Si}$ was $1.5 \%$ and $21.5 \%$, respectively. Because this was also valid in our study, the $s p^{3} /\left(s p^{2}+s p^{3}\right)$ ratio of $a$-C:H film deposited from TMS was concluded to be higher than that of $a$-C:H film deposited from acetylene. Consequently because of the $\mathrm{Si}$ in $a-\mathrm{C}: \mathrm{H}$ film, the number of $s p^{2}$ bonds, which account for color development, decreases and that of $s p^{3}$ bonds, which account for transparency, increases.

The compressive residual stress of $a$-C:H films deposited from acetylene and from TMS were measured. The curvature radius of the quartz glass substrates with $a-\mathrm{C}: \mathrm{H}$ film was measured and residual stress was calculated using Stoney's formula. Table 1 shows film thickness, curvature radius and residual stress. As we mentioned in the discussion on Raman 
Table 1 Compressive residual stress and thickness of $a-\mathrm{C}: \mathrm{H}$ films prepared from acetylene and TMS.

\begin{tabular}{c|cc}
\hline Source gas & Acetylene & TMS \\
\hline Thickness of $a$-C:H film [ $\mu \mathrm{m}]$ & 2.06 & 1.60 \\
Curvature radius [mm] & 485 & 984 \\
Residual stress [MPa] & 145 & 92 \\
\hline
\end{tabular}

Table 2 Composition and density of $a$-C:H films deposited from acetylene and TMS.

\begin{tabular}{c|cccc|c}
\hline & \multicolumn{4}{|c|}{ Atomic composition [at.\%] } & Film density $\left[\mathrm{g} / \mathrm{cm}^{3}\right]$ \\
Source gas & $\mathrm{C}$ & $\mathrm{Si}$ & $\mathrm{H}$ & $\mathrm{O}$ & \\
\hline Acetylene & 76 & 0 & 24 & 0 & 1.41 \\
TMS & 29 & 21 & 24 & 26 & 1.42 \\
\hline
\end{tabular}

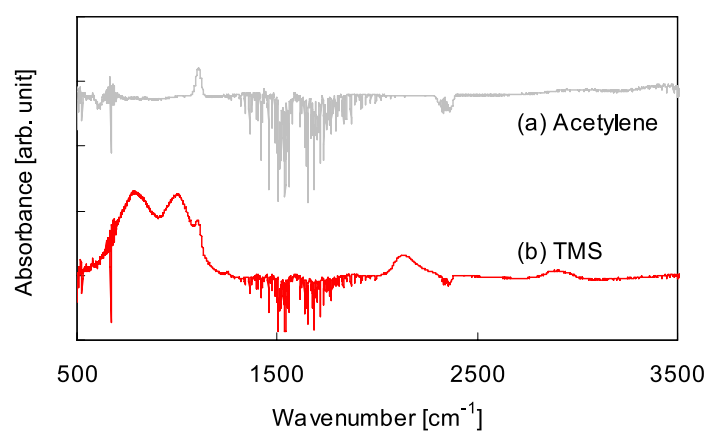

Fig. 7 FT-IR spectra of $a$-C:H films deposited from TMS and acetylene.

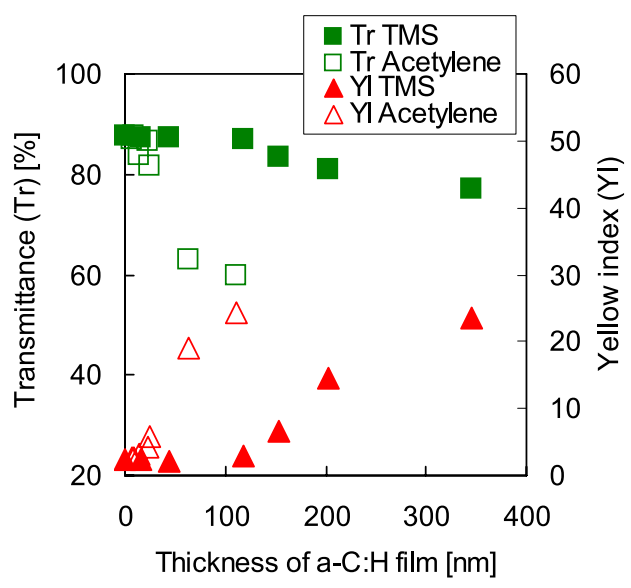

Fig. 8 Variations of transmittance and yellow index with thickness of $a$-C:H films deposited from acetylene and TMS.

spectroscopy, it is clear that introducting $\mathrm{Si}$ to the $a-\mathrm{C}: \mathrm{H}$ film reduces residual stress.

Two $a-\mathrm{C}: \mathrm{H}$ films were analyzed by RBS and ERDA. These results are shown in Table 2. The $a-\mathrm{C}: \mathrm{H}$ film deposited from TMS contained $\mathrm{Si}$ and $\mathrm{O}$ in addition to $\mathrm{C}$ and $\mathrm{H}$. The origin of $\mathrm{O}$ is considered to be the exposure to air ${ }^{(8)}$.

Figure 8 shows the dependence of the transmittance and yellow index on $a-\mathrm{C}: \mathrm{H}$ film thickness for the two kinds of gas sources of $a-\mathrm{C}: \mathrm{H}$ films. The much higher transparency of $a$-C:H film deposited from TMS was confirmed from these results. Figure 9 shows the appearance of the two $a-\mathrm{C}: \mathrm{H}$ films, and indicates that the $a-\mathrm{C}: \mathrm{H}$ film deposited from TMS has higher transparency than that from acetylene.

Figure 10 shows the dependence of the OTR on $a-\mathrm{C}: \mathrm{H}$ film thickness, for the two kinds of gas sources of $a$-C:H films. OTR of the $a$-C:H film deposited from acetylene was lower than that of film deposited from TMS. Thus, at the same film thickness, the $a$-C:H film deposited from acetylene has better gas barrier performance than that deposited from TMS.

Figure 11 shows the relationship between the optical property and gas barrier performance, for two kinds of gas sources of $a-\mathrm{C}: \mathrm{H}$ films. By introducting $\mathrm{Si}$ to the $a-\mathrm{C}: \mathrm{H}$ film, 


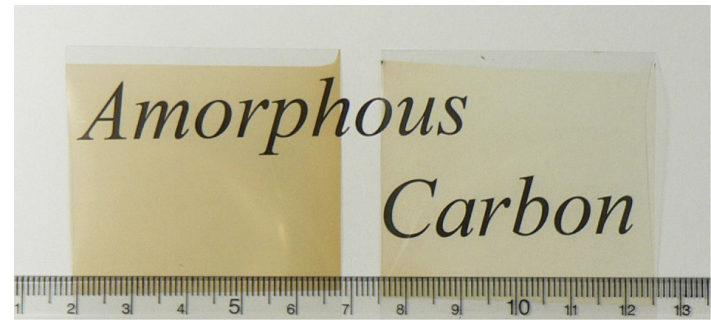

Source gas

(i) acetylene

(ii) TMS

Thickness of $a$-C:H film

$70 \mathrm{~nm}$

$200 \mathrm{~nm}$

Fig. 9 Images of $a$-C:H films deposited from acetylene and TMS.

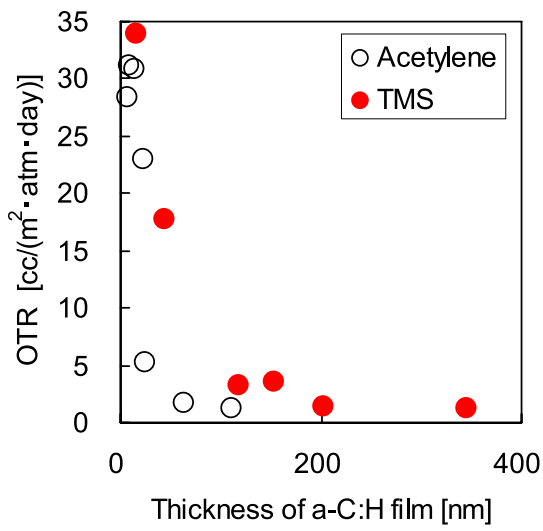

Fig. 10 Dependence of oxygen transmission rate on thickness of $a-\mathrm{C}: \mathrm{H}$ films deposited from acetylene and TMS.

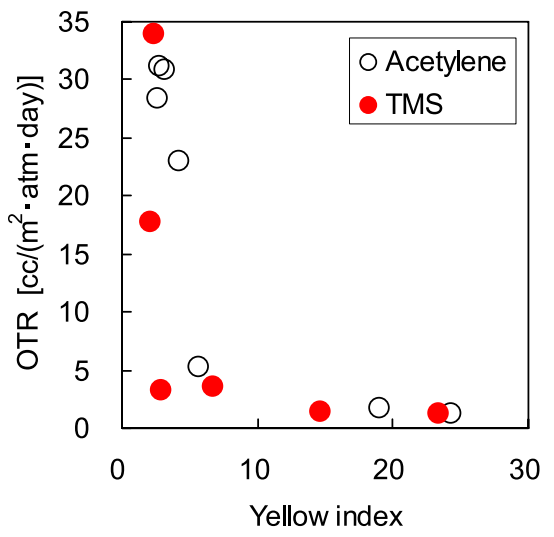

Fig. 11 Relationship between oxygen transmission rate and yellow index of films deposited from acetylene and TMS.

the optical property was greatly improved in spite of a small degradation of gas barrier performance, which approximates the zero point. In this case, thickness of the $a$-C:H film containing $\mathrm{Si}$ was larger than that of the film without $\mathrm{Si}$ at the same value of the yellow index.

\section{Conclusions}

$a-\mathrm{C}: \mathrm{H}$ films in $7 \sim 350 \mathrm{~nm}$ thick were fabricated from acetylene and TMS by the pulse plasma CVD method. The OTR, transmittance and yellow index of the $a-\mathrm{C}: \mathrm{H}$ films on PET substrates were measured. $a-\mathrm{C}: \mathrm{H}$ films prepared on $\mathrm{Si}$ substrates were analyzed by Raman scattering spectroscopy, FT-IR and RBS/ERDA. The results led us the following conclusion.

( 1 ) The thick $a-\mathrm{C}: \mathrm{H}$ film showed low transparency and high gas barrier performance. OTR at $a-\mathrm{C}: \mathrm{H}$ film thicknesses less than $20 \mathrm{~nm}$ was significantly higher than the calculated OTR, indicating that a high-oxygen transmission layer exists in the vicinity of the substrate.

( 2 ) By using TMS instead of acetylene as the source gas, the optical property was im- 
proved in spite of a small degradation of the gas barrier performance. The transmittance of the $a-\mathrm{C}: \mathrm{H} / \mathrm{Si}$ film for visible light was $87 \%$ with a relatively low OTR of $3.2 \mathrm{cc} /\left(\mathrm{m}^{2} \cdot \mathrm{atm} \cdot \mathrm{day}\right)$.

\section{References}

( 1 ) T. Yamamoto and H. Hyodo. Amorphous carbon overcoat for thin-film disk. Tribology International, Vol. 36, pp. 483-487, 2003.

( 2 ) Hiroki Akasaka and Naoto Ohtake. Electric properties of a-c:h/a-c:n:h/aluminum structure. Diamond and Related Materials, Vol. 17, pp. 673-675, 2008.

( 3 ) Hiroyuki Sugimura, Yoshiki Sato, Nobuhiro Tajima, and Osamu Takai. Field emission properties of amorphous carbon nitride thin films prepared by arc ion plating. Surface and Coatings Technology, Vol. 142-144, pp. 714-718, 2001.

( 4 ) Atsushi Ueda, Masaaki Nakachi, Seiji Goto, Hideo Yamakoshi, and Akira Shirakura. High speed and high gas barrier rotary dlc plasma coating system for pet bottles. Mitsubishi Heavy Industries, Ltd., Technical Review, Vol. 42, p. 42, 2005.

( 5 ) Akira Shirakura, Masaki Nakaya, Yoshinori Koga, Hideyuki Kodama, Terumitsu Hasebe, and Tetsuya Suzuki. Diamond-like carbon films for pet bottles and medical applications. Thin Solid Films, Vol. 494, pp. 84-91, 2006.

( 6 ) P. S. Guo, Z. Sun, S. M. Huang, and Y. Sun. Temperature effect on field emission properties and microstructures of polymer-based carbon films. J. Appl. Phys., Vol. 98, p. 74906, 2005.

( 7 ) G.A. Abbas, P. Papakonstantinou, T.I.T. Okpalugo, J.A. McLaughlin, J. Filik, and E. Harkin-Jones. The improvement in gas barrier performance and optical transparency of dlc-coated polymer by silicon incorporation. Thin Solid Films, Vol. 482, pp. 201-206, 2005.

( 8 ) M. Veres and M. Koós and S. Tóth and M. Füle and I. Pócsik and A. Tóth and M. Mohai and I. Bertóti. Characterisation of a-C:H and oxygen-containing Si:C:H films by Raman spectroscopy and XPS Diamond Relat. Mater., Vol. 14, pp.1051-1056, 2005. 